\title{
COST-EFFECTIVENESS \\ OF EXTRACORPOREAL MEMBRANE \\ OXYGENATION IN RESUSCITATION \\ OF PATIENTS WITH REFRACTORY CARDIAC \\ ARREST
}

\section{Klára Burišková, Vladimír Rogalewicz, Petr Ošt’ádal}

\section{Introduction}

Health care economists estimate that $40-50 \%$ of annual cost increases can be traced to new technologies or the intensified use of old ones (Callahan, 2008). However, any limitation of their application is massively criticized as unethical. Patients (supported by journalists) believe that new expensive technology will speed-up their treatment and miraculously enhance their quality of life, while physicians are fascinated by fanciful possibilities of state-of-the-art devices. Nevertheless, due to limited resources of health care, each particular utilization of a medical device should be put to the test of the clinical effectiveness and cost-effectiveness (Markiewicz, van Til, \& ljzerman, 2014; Rosina et al., 2014). The typical approach used above all in drugs is to calculate cost-effectiveness when the technology is in routine use. Due to special properties of medical devices (Rogalewicz \& Jurickova, 2014), it appears meaningful to start with cost-effectiveness analyses already during the development and testing phase (Fermont, Douw, Vondeling, \& ljzerman, 2016; Tarricone, Callea, Ogorevc, \& Rupel, 2017).

Health technology assessment (HTA) studies can provide healthcare decision makers with valuable data concerning effectiveness of medical interventions. The main purpose of an economic evaluation within HTA may be seen in measuring, valuing and comparing the costs and consequences of alternatives to support economic judgments about an intervention or a program. Technological innovations are associated with a significant public budget impact; hence, a high attention is paid to their cost-effectiveness. Cost analyses, the core of these studies, require detailed, exact and true inputs. In the Central and East Europe countries, this is common in drugs, while rather disregarded in other technologies including medical devices (Gulacsi et al., 2014; Soltes \& Gavurova, 2014).

This study analyses effectiveness of costs of the extracorporeal cardiopulmonary resuscitation (ECPR) in relation to the survival and quality of life of the patients. The studied intervention is regarded as experimental and non-standard. Hence, the economic analysis can help in decisions about further research and assessment of the innovation potential. The cost-effectiveness results are assessed from the healthcare provider's perspective under different preconditions and for the conventional treatment as the comparator. Retrospective data from the Department of Acute Cardiology, $\mathrm{Na}$ Homolce Hospital in Prague (see https://www.homolka.cz/en-CZ/about-us.html) are used. Two systems for extracorporeal membrane oxygenation (ECMO) - Levitronix (Thoratec Corporation, USA) and Cardiohelp (Maquet, Germany) - are compared.

\section{Background}

Outcomes of cardiac arrest have changed only modestly despite of modern approaches to cardiopulmonary resuscitation (Bednarczyk et al., 2014; Fagnoul et al., 2013; Gavurová \& Vagašová, 2016; Park et al., 2014; Soltes \& Gavurova, 2015). Extracorporeal life support has been recently introduced as a therapeutic option for refractory cardiac arrest. Resuscitative ECMO was first applied to cardiac arrest in 1976 (Mattox \& Beall, 1976), however, for a long time it was not used due to massive complications. Technology progress 
has led to better outcomes and has facilitated widespread utilization of veno-arterial (V-A) ECMO (Johnson et al., 2014; Lazzeri et al., 2013; Lequier \& de Caen, 2012). Nevertheless, the use of V-A ECMO in the resuscitation of adults in cardiac arrest has limited evidence (Ken \& Alain, 2014; Ostadal et al., 2014), while the situation is only little better in neonates and children (Huang et al., 2012; Lowry et al., 2013). Reports of survival following the ECPR for inhospital cardiac arrest in adults range from 28 to $42 \%$ in recent single-site retrospective reports (Avalli et al., 2012; Bednarczyk et al., 2014; Haneya et al., 2012; Kagawa et al., 2010; Le Guen et al., 2011), and the benefit for out-hospital cardiac arrest patient has been discussed and sometimes questioned (Fagnoul et al., 2013; Johnson et al., 2014; Kagawa et al., 2010; Ken \& Alain, 2014). The decision to initiate ECMO has become more difficult due to better availability but remaining uncertainties as who might benefit from it (Ken \& Alain, 2014; Ostadal et al., 2014; Ramanathan, Cove, Caleb, Teoh, \& Maclaren, 2015; Sakamoto et al., 2014). Current guidelines for resuscitation have been published by the International Liaison Committee on Resuscitation (ILCOR) consisting of the American Heart Association (AHA) and the European Resuscitation Council (ERC). In the Czech Republic, the ERC guidelines are observed. The current valid revision is from 2015 (Truhlar et al., 2015). ECPR should be considered as a rescue therapy for the patients in whom initial ALS measures are unsuccessful, and/or to facilitate specific interventions.

As of January 2015, more than 1,600 patients have received extracorporeal cardiopulmonary resuscitation with a $28 \%$ survival-to-discharge rate worldwide, according to the registry of the Extracorporeal Life Support Organization (see http://www.elso.org). No data from randomized trials exist on ECPR as a rescue treatment for cardiac arrest, and a randomized trial comparing ECPR with conventional cardiopulmonary resuscitation will likely never be performed for many reasons, including limited sample size, variations in regional and institutional practice, or institutional unwillingness to randomize patients (Johnson et al., 2014; Lowry et al., 2013). Patients referred to ECMO during a refractory cardiac arrest show nearly $100 \%$ mortality without this intervention; hence, ECMO represents the last chance to survive for them (Ostadal et al., 2014). Despite growing evidence from retrospective studies demonstrating improved survival rate with ECPR in refractory in-hospital (Athanasuleas, Buckberg, Allen, Beyersdorf, \& Kirsh, 2006; Avalli et al., 2012; Bednarczyk et al., 2014; Chen et al., 2008; Shin et al., 2011) and out-hospital cardiac arrest (Chen et al., 2006; Johnson et al., 2014; Le Guen et al., 2011; Morimura et al., 2011; Nagao et al., 2010; Sakamoto et al., 2014), a number of questions remain unanswered, and data on cost-effectiveness of this approach are still insufficient. Although the intervention is resource intensive, cost analyses have been rare (Atsumi et al., 2011; Clarke et al., 2014; Lowry et al., 2013; Mishra et al., 2010; Naess \& Steen, 2004; Paniagua et al., 2002; Peek et al., 2009; Roos et al., 2013; St-Onge, Fan, Mégarbane, HancockHoward, \& Coyte; Tseng, Wu, Tsai, Chen, \& Lin, 2011). The aim of this study is a retrospective cost-effectiveness analysis performed from the provider's perspective.

\section{Methods}

The study was designed as a retrospective observational comparative study of ECMO applied to cardiac arrest in the clinical practice of the Na Homolce Hospital in Prague. Records of the patient sample were extracted from authentic patients' records; the inclusion criteria were the intervention timespan between 1 January 2009 and 31 March 2014, the diagnosis, and the treatment method. The basic input diagnosis was (in terms of the International Classification of Diseased ICD-10) cardiac arrest (146) and/or cardiogenic shock (R570), both conditioned by the refractory course, when it was not possible to restore the coronary circulation by standard resuscitation techniques. Sixteen patients undergoing ECPR (all patients undergoing ECPR in the $\mathrm{Na}$ Homolce Hospital in the particular period) were included into the analysis (ECPR group), and the data were compared with 35 subjects with conventional CPR for refractory cardiac arrest (non-ECPR group). The conventional methods of CPR involve chest compression and artificial respiration (in hospitals supported by mechanical ventilation), i.e. without applying the ECMO system.

Two cost analyses were calculated. First, the costs were related to the survival time in a simple cost-effectiveness analysis (CEA). Then, the quality of life was also taken into account 
together with the survival time expressing the amount of QALYs as their product (Rogalewicz \& Bartak, 2017; Whitehead \& Ali, 2010), and a standard cost-utility analysis (CUA) in terms of costs per QALY was calculated. The health-related quality of life was determined for individual Cerebral Performance Categories (CPC) by Raina et al. and Stiell et al. (Raina, Callaway, Rittenberger, \& Holm, 2008; Stiell et al., 2003) using the Health Utility Index Mark 3 (HUI-3) (Whitehead \& Ali, 2010).

Mean values of costs were calculated per one patient in the respective group for the whole hospitalization. They include materials, pharmaceuticals, personal costs and overhead costs (per a bed and a day) according to the respective ward level (coronary care unit, ICU, standard ward). Average costs of utilization of the ECMO system for one patient including consumables are added. The price of the ECMO system was calculated on the basis of 5-year depreciations.

All prices are given in Czech crowns (CZK) and refer to the 2013 price level (with the exception of personal costs based on official national statistics for 2012 (Maskova, 2013)). Although it is not possible to simple recalculate prices using the exchange rate due to different purchasing power and salary level in different countries, for a quick reference one can start from the approximate exchange rates CZK/EUR $=27.50$ and $\mathrm{CZK} / \mathrm{USD}=24.50$ as of beginning February 2015 (see http://www.cnb.cz).

It is common in most healthcare systems to set a cost-effectiveness (C/E) threshold, i.e. the limit costs per QALY for which an intervention can be considered cost-effective (Rogalewicz \& Bartak, 2017). When discussing the cost-effectiveness threshold, the limit of three times the gross domestic product (GDP) per capita recommended by the World Health Organization (Rogalewicz \& Bartak, 2017;
WHO, 2002) is often referred to in the Czech Republic. According to the 2014 information of the Czech Statistical Office, GDP per capita was CZK 388,764 in the Czech Republic in 2013 (the last published results), which gives the $\mathrm{C} / \mathrm{E}$ threshold (three times this figure) of CZK 1,166,292.

\section{Results}

\subsection{Cost Calculation}

The purchase price of the devices was taken from the hospital's accounting. The price of the Cardiohelp system was CZK 2,000,000 and consumables are delivered in the average for CZK 120,000 for one patient. The price of the Levitronix system was CZK 600,000. Consumables cost CZK 220,000 and it is necessary to separately purchase the oxygenator for CZK 10,000 and two cannulas for CZK 7,000 each. Annual costs of service are CZK 23,000 for Levitronix and CZK 2,600 for Cardiohelp (in both cases, service for the first two years was included in the purchase price). Other devices are included in the overhead costs per a bed, which is CZK 17,500 per day for the coronary care unit, CZK 3,500 per day for the (intermediate) ICU, and CZK 1,700 per day for a standard bed.

As the hospital did not reveal staff salaries, the calculation of personal costs is based on national statistical data. Time spent by different staff categories were recorded in the hospital department, and subsequently multiplied by average salaries published by the Institute of Health Information and Statistics of the Czech Republic for 2012 (latest data published in the time of this research) (Maskova, 2013).

The mean total costs for one patient in the non-ECPR group were CZK 81,001; Tab. 1 shows their breakdown. The mean total costs in the ECPR group were CZK 788,432 in the case of the Cardiohelp system and CZK 885,044

Tab. 1: The mean total costs for one patient in the non-ECPR group

\begin{tabular}{l|c}
\multicolumn{1}{c|}{ Cost group } & Costs (CZK) \\
\hline Materials, pharmaceuticals & 51,660 \\
\hline Personal costs & 11,841 \\
\hline Costs per bed: coronary care unit & 17,500 \\
\hline Total & $\mathbf{8 1 , 0 0 1}$ \\
\hline
\end{tabular}


Tab. 2: The mean total costs for one patient in the ECPR group

\begin{tabular}{l|r|r}
\multirow{2}{*}{ Cost group } & \multicolumn{2}{c}{ Costs (CZK) } \\
\cline { 2 - 3 } & Cardiohelp system & \multicolumn{1}{c}{ Levitronix system } \\
\hline Materials, pharmaceuticals & 408,995 & 408,995 \\
\hline Personal costs & 86,776 & 86,776 \\
\hline Costs per bed: coronary care unit & 129,063 & 129,063 \\
\hline Costs per bed: ICU & 5,950 & 5,950 \\
\hline Costs per bed: standard ward & 3,570 & 3,570 \\
\hline ECMO system (depreciations + regular service) & 20,078 & 6,690 \\
\hline ECMO system - consumables & 134,000 & 244,000 \\
\hline Total & $\mathbf{7 8 8 , 4 3 2}$ & $\mathbf{8 8 5 , 0 4 4}$ \\
\hline
\end{tabular}

in the case of the Levitronix system. Their breakdown is shown in Tab. 2.

\subsection{Survival Time CEA}

When assessing the clinical effectiveness, average survival time was recorded for patients from the research sample of patients treated in the Department of Acute Cardiology of the $\mathrm{Na}$ Homolce Hospital. Tab. 3 shows average figures for the groups of patients with and without the ECPR. Clinical parameters are recorded for all patients during seven days after the cardiac arrest; survival time is monitored also after the discharge from the hospital in patients that survive. The results suggest that the death comes within 12 hours after the conventional cardiopulmonary resuscitation in the non-ECPR group. Thus, the neurologic deficit value is CPC 5, as all patients eventually die. In the ECPR group, eight out of sixteen patients survived. Four patients in this number reached CPC 1-2 with the average survival time of 20 months, and four patients ended with CPC 3-4 with the average survival time of 5 months. The other eight patients from the ECPR group died in average within 10 days, although connected to the ECMO system.

The cost-effectiveness ratio (C/E) was first calculated taking plain survival time for the effect. It resulted in relatively high values slightly different for both systems:

$\mathrm{C} / \mathrm{E}($ Cardiohelp $)=788,432 / 0.692=1,139,353$, $\mathrm{C} / \mathrm{E}($ Levitronix $)=885,044 / 0.692=1,278,965$,

although the costs of non-ECPR patients are incomparably lower, the C/E ratio is very high due to practically zero survival:

$C / E($ non-ECPR $)=81,001 / 0.001=81,001,000$.

\begin{tabular}{|c|c|c|c|c|}
\hline Tab. 3: & \multicolumn{4}{|c|}{$\begin{array}{l}\text { Overview of clinical effectiveness in the course of the cardiopulmonary } \\
\text { resuscitation }\end{array}$} \\
\hline \multirow{2}{*}{\multicolumn{2}{|c|}{$\begin{array}{l}\text { Treatment } \\
\text { (number of patients) }\end{array}$}} & \multirow{2}{*}{ CPC reached } & \multicolumn{2}{|c|}{ Average survival time } \\
\hline & & & (in years) & (in shorter units) \\
\hline \multicolumn{2}{|c|}{ Non-ECPR $(n=35)$} & CPC $5(100 \%)$ & 0.001 & 12 hours \\
\hline \multirow{3}{*}{\multicolumn{2}{|c|}{$\operatorname{ECPR}(n=16)$}} & CPC 1-2 (25\%) & 1.640 & 1 year and 8 months \\
\hline & & CPC 3-4 (25\%) & 0.410 & 5 months \\
\hline & & CPC $5(50 \%)$ & 0.027 & 9.8 days \\
\hline \multicolumn{2}{|c|}{ ECPR mean value } & & 0.692 & 8.3 months \\
\hline
\end{tabular}


These values were combined to get the incremental cost-effectiveness ratio (ICER) of ECPR towards non-ECPR treatment. The resulting ICER is CZK 1,023,778 and CZK 1,163,593 for Cardiohelp resp. Levitronix ECMO systems. The results of CEA are summarized in Tab. 6 .

\subsection{QALYs and CUA}

Health-related quality of life after cardiac arrest was evaluated by Stiell and Raina with their colleagues, who determined HUI-3 values related to CPCs (Raina et al., 2008; Stiell et al., 2003). QALYs for individual CPCs were evaluated by multiplying their HUI-3 values by the mean survival time in our patient sample. Resulting QALYs are shown in Tab. 4. The average utility for the ECPR group is 0.200 and for the non-ECPR group zero. Using the costs from Tabs. 1 and 2, we get the incremental cost- utility ratio (ICUR) for the treatment with ECMO compared to the conventional treatment (without ECPR). The values are CZK 3,537,155 in the case of Cardiohelp, and even CZK 4,020,215 in the case of Levitronix; both values are high above the cost-effectiveness threshold of CZK 1,166,292, which speaks against this intervention. However, if we calculate ICUR for patients with $C P C=1-2$ only, the results are quite different. Tab. 5 shows costs for this group of patients (they are higher than the mean costs due to better survival leading to a longer hospitalization). Taking these costs and the utility of 1.312 QALYs into account, we get ICUR equal to CZK 772,877 for Cardiohelp, and CZK 846514 for Levitronix. These figures are already below the $\mathrm{C} / \mathrm{E}$ threshold. If we were able to predict the neurological outcome of the intervention, it might lead to a precise selection of patients for utilizing ECMO in the case of

\begin{tabular}{|c|c|c|c|c|}
\hline Tab. 4: & \multicolumn{4}{|c|}{$\begin{array}{l}\text { HUI-3 values related to cerebral performance categories (CPC) } \\
\text { and the respective mean survival times and QALYs for the patient sample } \\
\text { from the } \mathrm{Na} \text { Homolce Hospital }\end{array}$} \\
\hline \multicolumn{2}{|c|}{ CPC and number of patients } & $\begin{array}{c}\text { HUI-3 (Raina et al., 2008; } \\
\text { Stiell et al., 2003) }\end{array}$ & $\begin{array}{c}\text { Mean survival time } \\
\text { [years] }\end{array}$ & QALYs \\
\hline \multicolumn{2}{|c|}{ CPC 1-2 $(n=4)$} & 0.8 & 1.64 & 1.312 \\
\hline \multicolumn{2}{|c|}{ CPC 3-4 $(n=4)$} & 0.35 & 0.41 & 0.146 \\
\hline \multicolumn{2}{|c|}{ CPC $5(n=8)$} & 0 & 0.027 & 0 \\
\hline \multicolumn{2}{|c|}{$\begin{array}{l}\text { Weighted average for ECPR } \\
\text { patients }(n=16)\end{array}$} & 0.29 & 0.692 & 0.200 \\
\hline
\end{tabular}

Source: Raina et al. (2008); Stiell et al. (2003)

Tab. 5: The mean total costs for one patient with $C P C=1-2$ in the ECPR group

\begin{tabular}{l|r|r}
\multirow{2}{*}{\multicolumn{1}{c|}{ Cost group }} & \multicolumn{2}{c}{$\begin{array}{c}\text { Costs (CZK) } \\
\text { (patients with CPC=1-2 only) }\end{array}$} \\
\cline { 2 - 3 } & Cardiohelp system & \multicolumn{1}{c}{ Levitronix system } \\
\hline Materials, pharmaceuticals & 586,009 & 586,009 \\
\hline Personal costs & 139,014 & 139,014 \\
\hline Costs per bed: coronary care unit & 196,875 & 196,875 \\
\hline Costs per bed: ICU & 11,900 & 11,900 \\
\hline Costs per bed: standard ward & 7,140 & 7,140 \\
\hline ECMO system (depreciations + regular service) & 20,078 & 6,690 \\
\hline ECMO system - consumables & 134,000 & 244,000 \\
\hline Total & $\mathbf{1 , 0 9 5 , 0 1 6}$ & $\mathbf{1 , 1 9 1 , 6 2 8}$ \\
\hline
\end{tabular}


Tab. 6: Results of the cost-effectiveness and the cost-utility analyses

\begin{tabular}{|c|c|c|c|c|}
\hline Analysis type & Intervention & $\begin{array}{l}\text { Costs } \\
{[C Z K]}\end{array}$ & $\begin{array}{c}\text { Average } \\
\text { survival time } \\
\text { [years] }\end{array}$ & $\begin{array}{c}\text { Result } \\
\text { [CZK/1-year survival] }\end{array}$ \\
\hline \multirow[t]{3}{*}{$\mathrm{C} / \mathrm{E}$ ratio } & ECPR (Cardiohelp) & 788,432 & 0.692 & $1,139,353$ \\
\hline & ECPR (Levitronix) & 855,044 & 0.692 & $1,278,965$ \\
\hline & non-ECPR & 81,001 & 0.001 & $81,001,000$ \\
\hline \multirow[t]{2}{*}{ ICER } & $\begin{array}{l}\text { ECPR (Cardiohelp) } \\
\text { vs. non-ECPR }\end{array}$ & $788,432-81,001$ & $0.692-0.001$ & $1,023,778$ \\
\hline & $\begin{array}{l}\text { ECPR (Levitronix) } \\
\text { vs. non-ECPR }\end{array}$ & $855,044-81,001$ & $0.692-0.001$ & $1,163,593$ \\
\hline Analysis type & Intervention & $\begin{array}{l}\text { Costs } \\
{[C Z K]}\end{array}$ & QALYs & $\begin{array}{c}\text { Result } \\
\text { [CZK/QALY] }\end{array}$ \\
\hline \multirow[t]{2}{*}{ ICUR } & $\begin{array}{l}\text { ECPR (Cardiohelp) } \\
\text { vs. non-ECPR } \\
\end{array}$ & $788,432-81,001$ & $0.200-0.000$ & $3,537,155$ \\
\hline & $\begin{array}{l}\text { ECPR (Levitronix) } \\
\text { vs. non-ECPR }\end{array}$ & $885,044-81,001$ & $0.200-0.000$ & $4,020,215$ \\
\hline \multirow{2}{*}{$\begin{array}{l}\text { ICUR } \\
\text { (patients with } \\
\text { CPC 1-2 only) }\end{array}$} & $\begin{array}{l}\text { ECPR (Cardiohelp) } \\
\text { vs. non-ECPR } \\
\end{array}$ & $1,095,016-81,001$ & $1.312-0.000$ & 772,877 \\
\hline & $\begin{array}{l}\text { ECPR (Levitronix) } \\
\text { vs. non-ECPR }\end{array}$ & $1,191,628-81,001$ & $1.312-0.000$ & 846,514 \\
\hline \multicolumn{4}{|c|}{ WHO (2002) recommended C/E threshold (three times GDP per capita) } & $1,166,292$ \\
\hline
\end{tabular}

Source: own calculation

Note: An intervention is considered cost-effective, if the ICUR is below the fixed C/E threshold; a commonly accepted threshold for the Czech Republic is indicated on the last line.

refractory cardiac arrest. In such a case, the intervention would be cost-effective. The results of CUA are summarized in Tab. 6 .

\section{Discussion}

The results of this retrospective observatory study pose several questions. It is obvious that utilization of the ECMO system in the refractory cardiac arrest gives the patient the last chance to be saved. The results from the $\mathrm{Na}$ Homolce Hospital support the conclusions of published studies that utilization of ECMO presents the last option in the treatment for the patients that, moreover, get into a heavy cardiogenic shock after the protracted resuscitation (Avalli et al., 2012; Cardarelli, Young, \& Griffith, 2009; Chen et al., 2006; Chen et al., 2008; Haneya et al., 2012; Kagawa et al., 2010; Le Guen et al., 2011; Massetti et al., 2005; Morimura et al., 2011; Shin et al., 2011). If the patient is not referred for ECMO, the death actually comes in $100 \%$ of cases.
However, when applying ECPR, the survival time cannot be taken for a single definite predictor of the treatment effect, since it does not reflect the actual state of the patient relative to his eventual quality of life. In many patients, different degree of brain damage appears after a protracted cardiopulmonary resuscitation (Atsumi et al., 2011). Hence, an indicator of the health-related quality of life (expressed in QALYs) or of the brain damage (in CPCs) is usually used in the assessment. In this research, we used CPC scores; they are easily convertible to QALYs (Raina et al., 2008; Stiell et al., 2003). Hence, CPCs allow an easy assessment of quality of life in the patients treated and successfully weaned from the ECMO system.

In the intensive medicine field, the decision about utilization of ECMO is still a clinical challenge; the intervention must be adopted in a relatively short time, and the decision is complicated due to insufficient results from clinical trials that are heterogenic and 
may give a quite controversial impression (Cardarelli et al., 2009). Due to the variability in populations studied, differences seem to appear based in the geographic composition of the respective samples, and also following from the differences in national healthcare systems. When comparing results of clinical effectiveness and cost-effectiveness, almost all European studies (Clarke et al., 2014; Hartz et al., 1990; Naess \& Steen, 2004; Paniagua et al., 2002; Plaisance et al., 1999; Raithel et al., 1989) were taken into consideration; both clinical and cost results obtained in these studies were mutually comparable. In the European average, CUA is in the region around 23,000 EUR/QALY $(\approx 632,500 \mathrm{CZK} / \mathrm{QALY}$ ) (Clarke et al., 2014; Mishra et al., 2010; Peek et al., 2009), while ICUR (the incremental cost-utility ratio) reaches 51,315 EUR $(\approx 1,411,000$ CZK) (Clarke et al., 2014; Roos et al., 2013). These results are comparable with those of ours. Greatest differences in costs were observed in Asian countries. The Japan study (Atsumi et al., 2011) suggests CUA in the range of 132,298 EUR/ QALY $(\approx 3,638,000$ CZK/QALY), while the Taiwan results (Tseng et al., 2011) were significantly lower than those from Europe.

In the Czech conditions, ICER for ECPR related to the conventional cardiopulmonary resuscitation was between CZK 1,023,778 (Cardiohelp) and CZK 1,163,593 (Levitronix) for one year of life. This is on the level of the costeffectiveness threshold (CZK 1,166,292). This is similar to the results of Clarke et al. (Clarke et al., 2014), whose GBP 53,527 per QALY is over the threshold applied in England (Devlin \& Parkin, 2004). Nevertheless, the National Health Service (NHS) recommends reimbursing ECPR in the case that there is no other option to save a human life. However, our results suggest that the increased costs of ECMO from the healthcare provider's perspective are costeffective above all from the point of view of CUA. The ICUR values are between 772,877 CZK/ QALY and 846,514 CZK/QALY for Cardiohelp and Levitronix respectively in patients with CPC $=1-2$. These figures point at the necessity of a good neurological result prediction.

The treatment outcome results in patients with the refractory cardiac arrest that appeared outside the hospital showed to be less favourable (Kagawa et al., 2010). There is a delay of the resuscitation due to the distance to hospital, which may make the survival chance worse. In these patients, the shortest possible time until connection to the ECMO system in a specialized centre is necessary. The research sample is affected by the uniqueness of the method that is not widespread in the Czech Republic, and thus also patients from outside the respective catchment area are included; in these patients, the delay in treatment may play a significant role in their survival and the resulting neurological state.

The natural question appears of which patients should receive this therapy. Based on the literary review, the criterion could be as follows: (1) the age below 75 years, (2) the spontaneous circulation is not restored within 20 minutes of the enlarged conventional cardiopulmonary resuscitation (Ostadal \& Belohlavek, 2013). Such criteria have also an important ethical side, as they decrease survival chances above all for older patients and also for patients resuscitated in distant areas without a specialized cardiocentre with the possibility of connecting the patient to the ECMO system. The issues of accessibility and of an equal access to the intervention that often is the last chance of life saving should be carefully considered.

\section{Conclusions}

Within the Czech healthcare system, ICER for ECPR related to the conventional cardiopulmonary resuscitation was between CZK 1,023,778 (Cardiohelp) and CZK 1,163,593 (Levitronix) for one year of life. The ICUR values were between 772,877 CZK/QALY (Cardiohelp) and 846,514 CZK/ QALY (Levitronix) in patients with CPC $=1-2$. These figures point at the necessity of a good neurological result prediction. Thus, it is much more promising for in-hospital than for outhospital cardiac arrest patients.

The treatment using the ECMO system is more expensive, though, in fact, it is the only chance for patients with cardiac arrest for a hopeful survival rate and quality of life after the intervention. Moreover, it falls below the cost-effectiveness threshold (however, it is only a supplementary criterion in the Czech Republic as well as in many other countries). Our data indicate that ECPR for refractory cardiac arrest might be cost effective despite the high costs per individual patient treated with this approach. Larger studies are, however, required to confirm these observations. 
The research leading to this paper was partly supported by the Ministry of Education, Youth and Sports of the Czech Republic within the "Institutional Support for Development of Research Organizations".

\section{References}

Athanasuleas, C., Buckberg, G., Allen, B., Beyersdorf, F., \& Kirsh, M. (2006). Sudden cardiac death: Directing the scope of resuscitation towards the heart and brain. Resuscitation, 70(1), 44-51. https://doi. org/10.1016/j.resuscitation.2005.11.017.

Atsumi, T., Sakamoto, T., Morimura, N., Nagao, K., Asai, Y., Yokota, H., Tahara, Y., Nara, S., Hase, M., Sato, S., Ariyoshi, K., \& Asaka, Y. (2011). AS11 Cost effectiveness analysis of ECPR - Result from SAVE-J the multicenter study. Resuscitation, 82. https://doi. org/10.1016/S0300-9572(11)70012-0.

Avalli, L., Maggioni, E., Formica, F., Redaelli, G., Migliari, M., Scanziani, M., Celotti, S., Coppo, A., Caruso, R., Ristagno, G., \& Fumagalli, R. (2012). Favourable survival of in-hospital compared to out-of-hospital refractory cardiac arrest patients treated with extracorporeal membrane oxygenation: an Italian tertiary care centre experience. Resuscitation, 83(5), 579-583. https://doi. org/10.1016/j.resuscitation.2011.10.013.

Bednarczyk, J. M., White, C. W., Ducas, R. A., Golian, M., Nepomuceno, R., Hiebert, B., Bueddefeld, D., Manji, R. A., Singal, R. K., Hussain, F., \& Freed, D. H. (2014). Resuscitative extracorporeal membrane oxygenation for in hospital cardiac arrest: A Canadian observational experience. Resuscitation, 85(12), 1713-1719. https://doi.org/10.1016/j. resuscitation.2014.09.026.

Callahan, D. (2008). Health care costs and Medical technology. In M. Crowley (Ed.), From Birth to Death and Bench to Clinic: The Hastings Center Bioethics Briefing Book for Journalists, Policymakers, and Campaigns (pp. 79-82). Garrison, NY: The Hastings Center.

Cardarelli, M. G., Young, A. J., \& Griffith, B. (2009). Use of extracorporeal membrane oxygenation for adults in cardiac arrest (E-CPR): a meta-analysis of observational studies. ASAIO Journal, 55(6), 581-586. https://doi.org/10.1097/MAT.0b013e3181bad907.

Chen, J., Ko, W., Yu, H., Lai, L., Huang, S., Chi, N., Tsai, C., Wang, S., Lin, F., \& Chen, Y. (2006). Analysis of the outcome for patients experiencing myocardial infarction and cardiopulmonary resuscitation refractory to conventional therapies necessitating extracorporeal life support rescue. Critical Care Medicine, 34(4), 950-957. https://doi. org/10.1097/01.CCM.0000206103.35460.1F.

Chen, Y., Lin, J., Yu, H., Ko, W., Jerng, J., Chang, W., Chen, W., Huang, S., Chi, N., Wang, C., Chen, L., Tsai, P., Wang, S., Hwang, J., \& Lin, F. (2008). Cardiopulmonary resuscitation with assisted extracorporeal lifesupport versus conventional cardiopulmonary resuscitation in adults with in-hospital cardiac arrest: an observational study and propensity analysis. Lancet, 372(9638), 554-561. https://doi.org/10.1016/S0140-6736(08)60958-7.

Clarke, A., Pulikottil-Jacob, R., Connock, M., Suri, G., Kandala, N-B., Maheswaran, H., Banner, N., \& Sutcliffe, P. (2014). Costeffectiveness of left ventricular assist devices (LVADs) for patients with advanced heart failure: analysis of the British NHS bridge to transplant (BTT) program. International Journal of Cardiology, 171(3), 338-345. https://doi. org/10.1016/j.ijcard.2013.12.015.

Devlin, N., \& Parkin, D. (2004). Does NICE have a cost-effectiveness threshold and what other factors influence its decisions? A binary choice analysis. Health Economics, 13(5), 437452. https://doi.org/10.1002/hec.864.

Fagnoul, D., Taccone, F. S., Belhaj, A., Rondelet, B., Argacha, J. F., Vincent, J. L., \& De Backer, D. (2013). Extracorporeal life support associated with hypothermia and normoxemia in refractory cardiac arrest. Resuscitation, 84(11), 1519-1524. https://doi.org/10.1016/j. resuscitation.2013.06.016.

Fermont, J. M., Douw, K. H. P., Vondeling, H., \& ljzerman, M. J. (2016). Ranking medical innovations according to perceived health benefit. Health Policy and Technology, 5(2), 156-165. https://doi.org/10.1016/j.hlpt.2016.02.009.

Gavurová, B., \& Vagašová, T. (2016). Regional differences of standardised mortality rates for ischemic heart diseases in the Slovak Republic for the period 1996-2013 in the context of income inequality. Health Economics Review, 6(1), 1-12. https://doi.org/10.1186/ s13561-016-0099-1.

Gulacsi, L., Rotar, A., Niewada, M., Loblova, O., Rencz, F., Petrova, G., Boncz, I., \& Klazinga, N. (2014). Health technology assessment in Poland, the Czech Republic, Hungary, Romania and Bulgaria. European 
Journal of Health Economics, 15, S13-S25. https://doi.org/10.1007/s10198-014-0590-8.

Haneya, A., Philipp, A., Diez, C., Schopka, S., Bein, T., Zimmermann, M., Lubnow, M., Luchner, A., Agha, A., Hilker, M., Hirt, S., Schmid, C., \& Müller, T. (2012). A 5-year experience with cardiopulmonary resuscitation using extracorporeal life support in nonpostcardiotomy patients with cardiac arrest. Resuscitation, 83(11), 1331-1337. https://doi. org/10.1016/j.resuscitation.2012.07.009.

Hartz, R., Locicero, J., Sanders, J. H., Frederiksen, J. W., Joob, A. W., \& Michaelis, L. L. (1990). Clinical-experience with portable cardiopulmonary bypass in cardiacarrest patients. Annals of Thoracic Surgery, 50(3), 437-441. https://doi.org/10.1016/00034975(90)90490-W.

Huang, S. C., Wu, E. T., Wang, C. C., Chen, Y. S., Chang, C. I., Chiu, I. S., Ko, W. J., \& Wang, S. S. (2012). Eleven years of experience with extracorporeal cardiopulmonary resuscitation for paediatric patients with in-hospital cardiac arrest. Resuscitation, 83(6), 710-714. https://doi.org/10.1016/j.resuscitation.2012.01.031.

Johnson, N. J., Acker, M., Hsu, C. H., Desai, N., Vallabhajosyula, P., Lazar, S., Horak, J., Wald, J., McCarthy, F., Rame, E., Gray, K., Perman, S. M., Becker, L., Cowie, D., Grossestreuer, A., Smith, T., \& Gaieski, D. F. (2014). Extracorporeal life support as rescue strategy for out-of-hospital and emergency department cardiac arrest. Resuscitation, 85(11), 1527-1532. https://doi.org/10.1016/j. resuscitation.2014.08.028.

Kagawa, E., Inoue, I., Kawagoe, T., Ishihara, M., Shimatani, Y., Kurisu, S., Nakama, Y., Dai, K., Takayuki, O., Ikenaga, H., Morimoto, Y., Ejiri, K., \& Oda, N. (2010). Assessment of outcomes and differences between in- and out-of-hospital cardiac arrest patients treated with cardiopulmonary resuscitation using extracorporeal life support. Resuscitation, 81(8), 968-973. https://doi.org/10.1016/j. resuscitation.2010.03.037.

Ken, P., \& Alain, V. (2014). What's new in ECMO: scoring the bad indications. Intensive Care Medicine, 40(11), 1734-1737. https://doi. org/10.1007/s00134-014-3455-9.

Lazzeri, C., Bernardo, P., Sori, A., Innocenti, L., Stefano, P., Peris, A., Gensini, G. F., Valente, S. (2013). Venous-arterial extracorporeal membrane oxygenation for refractory cardiac arrest: a clinical challenge. European Heart Journal: Acute
Cardiovascular Care, 2(2), 118-126. https://doi. org/10.1177/2048872613484687.

Le Guen, M., Nicolas-Robin, A., Carreira, S., Raux, M., Leprince, P., Riou, B., \& Langeron, O. (2011). Extracorporeal life support following out-of-hospital refractory cardiac arrest. Critical Care, 15(1), R29. https://doi.org/10.1186/cc9976.

Lequier, L., \& de Caen, A. (2012). Pediatric ECPR: Standard of care? Resuscitation, 83(6), 665-666. https://doi.org/10.1016/j. resuscitation.2012.03.012.

Lowry, A. W., Morales, D. L. S., Graves, D. E., Knudson, J. D., Shamszad, P., Mott, A. R., Cabrera, A. G., \& Rossano, J. W. (2013). Characterization of Extracorporeal Membrane Oxygenation for Pediatric Cardiac Arrest in the United States: Analysis of the Kids' Inpatient Database. Pediatric Cardiology, 34(6), 1422-1430. https://doi.org/10.1007/s00246-013-0666-8.

Markiewicz, K., van Til, J., \& IJzerman, M. (2014). Medical devices early assessment methods: systematic literature review. International Journal of Technology Assessment in Health Care, 30(2), 137-146. https://doi. org/10.1017/S0266462314000026.

Maskova, E. (2013). Wages and salaries in health services in 2012. Praha: Institute of Health Information and Statistics of the Czech Republic.

Massetti, M., Tasle, M., Le Page, O., Deredec, R., Babatasi, G., Buklas, D., Thuaudet, S., Charbonneau, P., Hamon, M., Grollier, G., Gerard, J. L., \& Khayat, A. (2005). Back from irreversibility: Extracorporeal life support for prolonged cardiac arrest. Annals of Thoracic Surgery, 79(1), 178-184. https://doi. org/10.1016/j.athoracsur.2004.06.095.

Mattox, K. L., \& Beall, A. C., Jr. (1976). Resuscitation of the moribund patient using portable cardiopulmonary bypass. Ann Thorac Surg., 22(5), 436-442.

Mishra, V., Svennevig, J. L., Bugge, J. F., Andresen, S., Mathisen, A., Karlsen, H., Khushi, I., \& Hagen, T. P. (2010). Cost of extracorporeal membrane oxygenation: evidence from the Rikshospitalet University Hospital, Oslo, Norway. European Journal of Cardio-thoracic Surgery, 37(2), 339-342. https://doi.org/10.1016/j.ejcts.2009.06.059.

Morimura, N., Sakamoto, T., Nagao, K., Asai, Y., Yokota, H., Tahara, Y., Atsumi, T., Nara, S., \& Hase, M. (2011). Extracorporeal cardiopulmonary resuscitation for out-ofhospital cardiac arrest: A review of the Japanese 
literature. Resuscitation, 82(1), 10-14. https://doi.org/10.1016/j.resuscitation.2010.08.032.

Naess, A., \& Steen, P. (2004). Long term survival and costs per life year gained after out-of-hospital cardiac arrest. Resuscitation, 60(1), 57-64. https://doi.org/10.1016/S03009572(03)00262-4.

Nagao, K., Kikushima, K., Watanabe, K., Tachibana, E., Tominaga, Y., Tada, K., Ishii, M., Chiba, N., Kasai, A., Soga, T., Matsuzaki, M., Nishikawa, K., Tateda, Y., Ikeda, H., \& Yagi, T. (2010). Early Induction of Hypothermia During Cardiac Arrest Improves Neurological Outcomes in Patients With Out-of-Hospital Cardiac Arrest Who Undergo Emergency Cardiopulmonary Bypass and Percutaneous Coronary Intervention. Circulation Journal, 74(1), 77-85. https://doi.org/10.1253/circj.CJ09-0502.

Ostadal, P., \& Belohlavek, J. (2013). ECMO: extrakorporálnímembránováoxygenace:manuál pro použití u dospělých [ECMO: extracorporeal membrane oxygenation: a manual for utilization in adults]. Praha: Maxdorf.

Ostadal, P., Kruger, A., Vondrakova, D., Kmonicek, P., Mates, M., Skabradova, M., Horakova, S., Jehlicka, P., Doubek, D., Kopriva, K., Janotka, M., \& Neuzil, P. (2014). VA ECMO in the management of non-surgical patients with cardiogenic shock and cardiac arrest. Intensive Care Medicine, 40, S129-S129.

Paniagua, D., Lopez-Jimenez, F., Londono, J., Mangione, C., Fleischmann, K., \& Lamas, G. (2002). Outcome and cost-effectiveness of cardiopulmonary resuscitation after in-hospital cardiac arrest in octogenarians. Cardiology, 97(1), 6-11. https://doi.org/10.1159/000047412.

Park, S. B., Yang, J. H., Park, T. K., Cho, Y. H., Sung, K., Chung, C. R., Park, C. M., Jeon, K., Song, Y. B., Hahn, J.-Y., Choi, J.-H., Choi, S.-H., Gwon, H.-C., Suh, G. Y. (2014). Developing a risk prediction model for survival to discharge in cardiac arrest patients who undergo extracorporeal membrane oxygenation. International Journal of Cardiology, 177(3), 1031-1035. https://doi. org/10.1016/j.ijcard.2014.09.124.

Peek, G., Mugford, M., Tiruvoipati, R., Wilson, A., Allen, E., Thalanany, M. M., Hibbert, C. L., Truesdale, A., Clemens, F., Cooper, N., Firmin, R. K., \& Elbourne, D. (2009). Efficacy and economic assessment of conventional ventilatory support versus extracorporeal membrane oxygenation for severe adult respiratory failure (CESAR): a multicentre randomised controlled trial. Lancet, 374(9698), 1351-1363. https://doi.org/10.1016/S01406736(09)61069-2.

Plaisance, P., Lurie, K., Vicaut, E., Adnet, F., Petit, J., Epain, D., Ecollan, P., Gruat, R., Cavagna, P., Biens, J., \& Payen, D. (1999). A comparison of standard cardiopulmonary resuscitation and active compressiondecompression resuscitation for out-ofhospital cardiac arrest. New England Journal of Medicine, 341(8), 569-575. https://doi. org/10.1056/NEJM199908193410804.

Raina, K., Callaway, C., Rittenberger, J., \& Holm, M. (2008). Neurological and functional status following cardiac arrest: Method and tool utility. Resuscitation, 79(2), 249-256. https://doi. org/10.1016/j.resuscitation.2008.06.005.

Raithel, S. C., Swartz, M. T., Braun, P. R., Dake, S. B., Taub, J. O., Zambie, M. A., Miller, L. W., Deligonul, U., McBride, L. R., \& Pennington, D. G. (1989). Experience with an emergency resuscitation system. ASAIO Trans., 35(3), 475-477.

Ramanathan, K., Cove, M. E., Caleb, M. G., Teoh, K. L. K., \& Maclaren, G. (2015). Ethical Dilemmas of Adult ECMO: Emerging Conceptual Challenges. Journal of Cardiothoracic and Vascular Anesthesia, 29(1), 229-233. https://doi.org/10.1053/j.jvca.2014.07.015.

Rogalewicz, V., \& Bartak, M. (2017). QALYs and cost-effectiveness thresholds: critical reflections. In Central European Conference in Finance and Economics (CEFE 2017), Herlany, Slovakia.

Rogalewicz, V., \& Jurickova, I. (2014). Specificities of Medical Devices Affecting Health Technology Assessment Methodology. In Proceedings IWBBIO2014: International WorkConference on Bioinformatics and Biomedical Engineering, Vols 1 and 2 (pp. 1229-1234).

Roos, J. B., Doshi, S. N., Konorza, T., Palacios, I., Schreiber, T., Borisenko, O. V., \& Henriques, J. P. S. (2013). The costeffectiveness of a new percutaneous ventricular assist device for high-risk $\mathrm{PCl}$ patients: mid-stage evaluation from the European perspective. Journal of Medical Economics, 16(3), 381-390. https://doi.org/10.3111/136969 98.2012.762004.

Rosina, J., Rogalewicz, V., Ivlev, I., Juřičková, I., Donin, G., Jantosová, N., Vacek, J., Otawova, R., \& Kneppo, P. (2014). Health Technology Assessment for Medical Devices. 
Lekar a technika - Clinician and Technology, 44(3), 23-36.

Sakamoto, T., Morimura, N., Nagao, K., Asai, Y., Yokota, H., Nara, S., Hase, M., Tahara, Y., \& Atsumi, T. (2014). Extracorporeal cardiopulmonary resuscitation versus conventional cardiopulmonary resuscitation in adults with out-of-hospital cardiac arrest: A prospective observational study. Resuscitation, 85(6), 762-768. https://doi.org/10.1016/j. resuscitation.2014.01.031.

Shin, T., Choi, J., Jo, I., Sim, M., Song, H., Jeong, Y., Song, Y. B., Hahn, J. Y., Choi, S. H., Gwon, H. C., Jeon, E. S., Sung, K., Kim, W. S., \& Lee, Y. (2011). Extracorporeal cardiopulmonary resuscitation in patients with inhospital cardiac arrest: A comparison with conventional cardiopulmonary resuscitation. Critical Care Medicine, 39(1), 1-7. https://doi. org/10.1097/CCM.0b013e3181feb339.

Soltes, M., \& Gavurova, B. (2015). Quantification and comparison of avoidable mortality - casual relations and modification of concepts. Technological and Economic Development of Economy, 21(6), 917-938. https://doi.org/10.3846/20294913.2015.1106421.

Soltes, V., \& Gavurova, B. (2014). The functionality comparison of the health care systems by the analytical hierarchy process method. E\&M Ekonomie a Management, 17(3), 100-117. https://doi.org/10.15240/tul/001/20143-009.

St-Onge, M., Fan, E., Mégarbane, B., Hancock-Howard, R., \& Coyte, P. C. (2015). Venoarterial extracorporeal membrane oxygenation for patients in shock or cardiac arrest secondary to cardiotoxicant poisoning: A cost-effectiveness analysis. Journal of Critical Care, 30(2), e437-e414. https://doi. org/10.1016/j.jcrc.2014.10.010.

Stiell, I., Nichol, G., Wells, G., De Maio, V., Nesbitt, L., Blackburn, J., \& Spaite, D. (2003). Health-related quality of life is better for cardiac arrest survivors who received citizen cardiopulmonary resuscitation. Circulation, 108(16), 1939-1944. https://doi.org/10.1161/01. CIR.0000095028.95929.B0.
Tarricone, R., Callea, G., Ogorevc, M., \& Rupel, V. P. (2017). Improving the Methods for the Economic Evaluation of Medical Devices. Health Economics, 26, 70-92. https://doi. org/10.1002/hec.3471.

Truhlar, A., Deakin, C. D., Soar, J., Khalifa, G. E. A., Alfonzo, A., Bierens, J., Brattebo, G., Brugger, H., Dunning, J., Hunyadi-Anticevic, S., Koster, R. W., Lockey, D. J., Lott, C., Paal, P., Perkins, G. D., Sandronis, C., Thies, K. C., Zideman, D. A., \& Nolan, J. P. (2015). European Resuscitation Council Guidelines for Resuscitation 2015 Section 4. Cardiac arrest in special circumstances. Resuscitation, 95, 148-201. https://doi.org/10.1016/j. resuscitation.2015.07.017.

Tseng, Y., Wu, M., Tsai, F., Chen, H., \& Lin, P. (2011). Costs Associated with Extracorporeal Life Support Used in Adults: A Single-Center Study. Acta Cardiologica Sinica, 27(4), 221-228.

Whitehead, S., \& Ali, S. (2010). Health outcomes in economic evaluation: the QALY and utilities. British Medical Bulletin, 96(1), 5-21. https://doi.org/10.1093/bmb/ldq033.

WHO. (2002). The World Health Report 2002. Reducing Risks, Promoting Healthy Life. Geneva: World Health Organization.

Ing. Klára Burišková Czech Technical University in Prague CzechHTA

Faculty of Biomedical Engineering Czech Republic kburiskova@gmail.com

doc. Vladimír Rogalewicz, CSc. Czech Technical University in Prague CzechHTA

Faculty of Biomedical Engineering Czech Republic rogalewicz@fbmi.cvut.cz

doc. MUDr. Petr Ošt'ádal, Ph.D., FESC $\mathrm{Na}$ Homolce Hospital Czech Republic petr.ostadal@homolka.cz 


\title{
Abstract
}

\section{COST-EFFECTIVENESS OF EXTRACORPOREAL MEMBRANE OXYGENATION IN RESUSCITATION OF PATIENTS WITH REFRACTORY CARDIAC ARREST}

\author{
Klára Burišková, Vladimír Rogalewicz, Petr Ošt'ádal
}

Extracorporeal cardiopulmonary resuscitation (ECPR) has been recently introduced as a therapeutic option for refractory cardiac arrest. Despite growing evidence demonstrating improved survival rate, a number of questions remains unanswered and data on cost-effectiveness are still insufficient. The paper is based on a retrospective observational comparative study of authentic clinical data from patient records. Incremental cost-effectiveness and cost-utility analyses were performed from health care provider's perspective. Sixteen patients undergoing ECPR were included into the analysis and their data were compared with 35 subjects with conventional CPR for refractory cardiac arrest. In the ECPR group eight out of sixteen patients were weaned from ECMO, four of them with good neurological outcomes (CPC 1-2); three patients survived one year with CPC 1-2, one patient survived one year with severe neurological dysfunction (CPC 3), and one patient with persisting coma (CPC 4). In comparison, in the non-ECPR group all patients died within 24 hours. In the ECPR group, the average annual costs per patient reached CZK 885,044 (Levitronix Centrimag), and CZK 788,432 (Cardiohelp) (the 2013 price level). CUA revealed 3,961,970 CZK QALY with Cardiohelp, and 4,447,457 CZK/QALY with Levitronix. However, if only patients with CPC 1-2 were included into the analysis, the cost-utility ratio decreased below the unofficial Czech cost-effectiveness threshold. Our data indicate that ECPR for refractory cardiac arrest may be cost-effective despite high costs per individual patients, especially if we were able to better select patients for this intervention based on a reliable prediction of the neurological outcome.

Key Words: Cost-effectiveness, cost-utility, extracorporeal cardiopulmonary resuscitation, ECPR, refractory cardiac arrest.

JEL Classification: 112.

DOI: 10.15240/tul/001/2019-2-011 